\title{
"If there is a job description I don't think I've read one": a case study of programme leadership in a UK pre-1992 university
}

\section{Abstract}

This paper reports on an exploratory study of the role of programme leaders (PLs) in a pre-1992 university, based on interviews with PLs (7) and a survey of taught Masters students (54) in a single school. The study elicits PLs' activities, most of which might be categorised as managerial and administrative, with leadership required intermittently; the preeminent role is in managing programme quality. The study finds that institutional guidelines overlook important aspects of PLs' work (such as organising enrichment activities and student advocacy) which affect the quality of provision; and findings challenge the notion that PLs are engaged in a 'disesteemed' service.

\section{Introduction}

Programme leaders (PLs) have been identified as playing a key role in higher education institutes (HEls), ensuring the relevance (Howson, 2012) and quality of learning (Vilkinas and Ladyshewsky, 2011), and providing academic leadership for the programme delivery team (Millburn, 2010). Yet, in common with other areas of higher education (Evans, 2012), the role of PLs is relatively un-researched and illdefined, particularly in pre-1992 HEls. In seeking to address this gap, this exploratory case study investigates the perceived role of PLs in a single school.

\section{Roles in Higher Education}

An inquiry into roles in the workplace is informed by a consideration of professionalism. Evans (2008) observes that a broad consensus of interpretations of professionalism regard it as an "externally imposed, articulated perception of what lies within the parameters of a profession's collective remit and responsibilities" (2008: 23). This is consistent with a functionalist view of roles, in contrast with a more dynamic, socially-defined nature of a role, and the impact of an individual practitioner's perceptions, practices or agency. In her conceptual study of professionalism, Evans' (2008) identifies the potentially stark difference between 
what is 'officially set down' as the roles and responsibilities of a profession, and what is actually enacted.

While Ramsden (1998) directs his study of academic leadership primarily towards "middle managers...called heads of academic departments" (p.5), Knight and Trowler (2001) argue that in many cases PLs have a comparable academic leadership role to heads of department-because, if one takes the workgroup as the significant unit of analysis, programme and academic teams are 'departments in miniature' (2001: vii). They argue that institutional documents and guidelines-such as role descriptions-are bereft of meaning until interpreted by a workgroup; only through discussion and negotiation does institutional documentation acquire significance (Trowler \& Knight, 2000).

Elsewhere, Knight and Trowler (2001) argue that when it comes to providing services, academics have a large degree of autonomy in interpreting and enacting policy; they are like 'street-level bureaucrats' who

have considerable power because of the discretion they must exercise in making decisions about the people they interact with...and in decisions about whether, and how, to apply rules...They may...modify their conception of their job so that any dissonance between what they are supposed to do and what they actually do is minimised. (2001: 4-5)

This would suggest that, in addition to the workgroup, the service users themselves might have an interesting perspective on the roles of different academics within HEls-as developed through their experience of interactions. In advocating the workgroup as a unit of analysis, Trowler and Knight overlook input from students as service users, although elsewhere this perspective has been used to inform a deeper understanding of issues in HEls (e.g. Evans \& Abbott, 1998).

\section{Service}

A traditional perspective on academics' work is that it is directed towards the discovery, conservation, refinement and transmission of knowledge (Tight, 2009). This overlooks the proliferation of non-teaching/research roles and responsibilities undertaken by academics, such as PLship, multimedia or educational technology specialism, etc. (Kogan \& Teichler, 2007). Tight regards such activities as occupying 
the borderland between the traditional knowledge creation/transmission function of academics; they "clearly involve academic expertise, but are often considered as 'second-tier' activities" (2009: 411), while Krause (2009) refers to academic managers and knowledge workers who undertake administrative and other duties as 'boundary-spanners'.

Academics' work has been presented as a teaching-service-research triad (Krause, 2009). While this is clearly an oversimplification (as teaching and research are services in themselves), it is helpful in directing attention towards the additional elements of academics' work. Based on interviews with academics from a range of post-industrialised countries, MacFarlane (2007) identifies five overlapping communities served by academics: students, colleagues, their institutions, their disciplines or professions, and the public (p264). Examples of service for each community could be given as follows:

- Student service - academic and pastoral support, writing references.

- Collegial service - mentoring or supporting peers, sharing teaching resources.

- Institutional service - committee membership, programme leadership.

- Discipline/professional service - peer-reviewing a journal, organising a conference.

- Public service - public lectures, advising government.

By serving the five communities through such activities, academics demonstrate their 'academic citizenship'. MacFarlane argues that service to each community attracts varying levels of esteem (see Figure 1). 


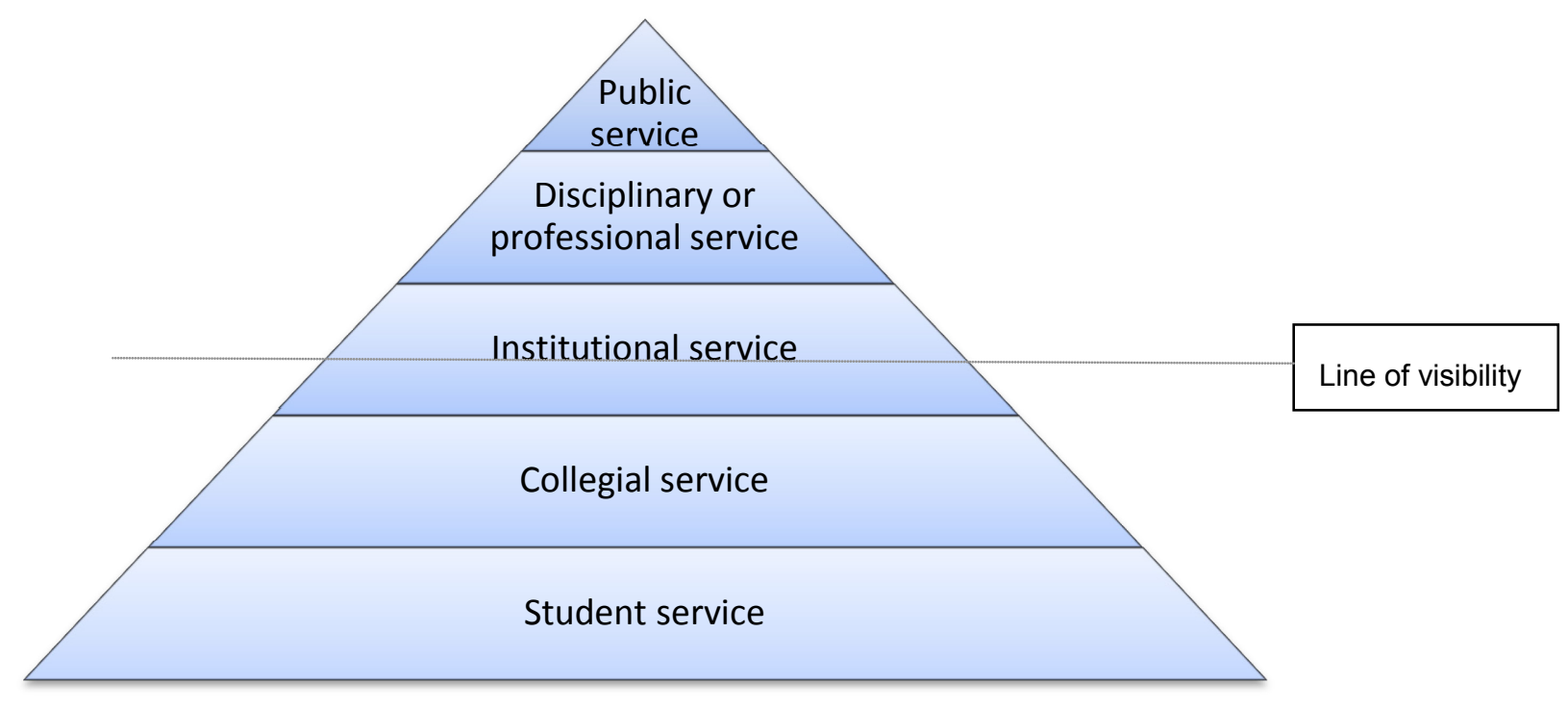

Figure 1 The service pyramid (adapted from MacFarlane, 2007: 265)

The pyramid does not reflect the relative importance of service to each community, but the comparative esteem associated with it, as reflected in institutional, disciplinary, professional or public rewards and recognition. MacFarlane's respondents felt that much of their service to students and colleagues went unrecognised, and he suggested a 'line of visibility' separating esteemed from disesteemed service.MacFarlane feels that the disesteem of service roles (compared to teaching and research) is due to the absence of national or institutional frameworks for judging such activities. He argues that institutions should take academics' service activities more seriously, and develop a framework for evidencing performance along with criteria for rewards and recognition. It is not difficult to envisage how the outcome of performance criteria for service roles would lead to more paperwork (as Morley [2003] points out, managerialism is 'grammatocentric'), and it is questionable whether this would lead to academics feeling greater esteem or frustration.

\section{Previous Research into Programme Leadership}

Fuzziness is characteristic of the role for which 'programme leader' is the preferred designation, but which is also variously known as course director, course leader, programme chair, programme convenor and programme coordinator (Johnston \& 
Westwood, 2007). Few formal studies focus exclusively on PLship: there are two peer-reviewed articles and one HEA-sponsored study (see Table 1), in addition to which Edinburgh Napier University has published institutional reports (McLeod, 2010; Howson, 2012) on the role and its support needs, and there is an HEA study (Blackmore et al., 2007) on the professional learning of programme and module leaders, which does not distinguish between the two roles.

Table 1 Studies of programme leadership

\begin{tabular}{|c|c|c|c|c|}
\hline Institution/s & $\begin{array}{c}\text { Sample } \\
\text { composition } \\
\text { \& data } \\
\text { collection } \\
\text { methods }\end{array}$ & Area of study & Format & Author/s \\
\hline $\begin{array}{l}\text { Post-1992 } \\
\text { English } \\
\text { university }\end{array}$ & $\begin{array}{l}9 \text { PLs - } \\
\text { focus group } \\
26 \text { PLs - } \\
\text { survey }\end{array}$ & $\begin{array}{l}\text { Professional development } \\
\text { needs of programme leaders }\end{array}$ & $\begin{array}{l}\text { Report } \\
\text { of HEA } \\
\text { study }\end{array}$ & $\begin{array}{l}\text { Johnston \& } \\
\text { Westwood (2007) }\end{array}$ \\
\hline $\begin{array}{l}\text { Post-1992 } \\
\text { UK } \\
\text { university }\end{array}$ & $\begin{array}{l}8 \text { PLs + } 4 \\
\text { colleagues - } \\
\text { interview }\end{array}$ & $\begin{array}{l}\text { The role of PLs as academic } \\
\text { leaders }\end{array}$ & $\begin{array}{l}\text { Peer- } \\
\text { reviewed } \\
\text { article }\end{array}$ & Millburn (2010) \\
\hline $\begin{array}{l}\text { Four } \\
\text { Australian } \\
\text { universities }\end{array}$ & $\begin{array}{l}90 \text { PLs + } 710 \\
\text { non-PLs - } \\
\text { survey }\end{array}$ & $\begin{array}{l}\text { Leadership behaviour and } \\
\text { effectiveness }\end{array}$ & $\begin{array}{l}\text { Peer- } \\
\text { reviewed } \\
\text { article }\end{array}$ & $\begin{array}{l}\text { Vilkinas \& } \\
\text { Ladyshewsky } \\
\text { (2011) }\end{array}$ \\
\hline
\end{tabular}

All studies in the UK context focus on post-1992 universities and common themes include: the pivotal nature of the role of $\mathrm{PL}$; its ill-defined nature; the balance between administration and leadership in the role; and its impoverished status.

Pivotal Role 
PLs are widely identified as occupying a unique and pivotal role within HEls, "the bridge between the multiple stakeholders" (Vilkinas and Ladyshewsky, 2011: 123). They act as an interface for HEls between the workplace (Milburn, 2010) and the market (Howson, 2012), mediate institutional policies into learning opportunities, and are ultimately responsible for the quality of such learning (Millburn, 2010; Vilkinas and Ladyshewsky, 2011); they also shape a programme's identity, bonding modules (Howson, 2012) and determining a programme's future direction (Millburn, 2010).

\section{Fuzzy Role}

A persistent fuzziness surrounds the role. Milburn (2010) identifies variations in the role across the sector regarding budgetary control and line management responsibilities, and such variations also occur within institutions (McLeod, 2010). Blackmore et al. draw on the work of Eraut to explain this, pointing out that "Staff tend to learn the process 'on the job'. Expertise is tacit, situated in a specific context and learned through observation of others" (2007: 3). This can result in PLs themselves questioning their own understanding of their role and their ability to evaluate their own performance.

I don't have any control of anything. Until something goes wrong and then because I am Programme Leader the buck stops with me. (Anonymous PL in McLeod, 2010)

In discussion with PLs at Edinburgh Napier University, McLeod (2010) identifies widespread uncertainty over the precise remit of the role, and a lack of institutional support, combined with an unreasonable degree of accountability.

\section{Balancing Administration, Management and Leadership}

While academic leadership is acknowledged as a feature of the role (McLeod, 2010; Milburn, 2010), there is broad agreement that administrative and management activities are the prime responsibilities. Some efforts have been made to quantify the balance of these activities. For example, Howson (2012) reports that in Edinburgh Napier University, PLs spend up to $40 \%$ of their time on 'leadership activities', while $20-50 \%$ is spent on administration; a median figure would be helpful here, and there is every reason to challenge the meaningfulness of such figures. A report from the 
same university published two years previously contains the following assertion from one PL:

I am an administrator - I just fire fight and respond to problems. My post has nothing to do with leadership. (Anonymous PL in McLeod, 2010: 13)

Researchers have identified a lack of recognition and respect afforded to the role, which might reflect the comparative 'invisibility' of PLs' service efforts for students (see Figure 1). It has led to feelings of isolation in their work (Howson, 2012), and is consequently regarded by some academics as a 'career killer' (Vilkinas and Ladyshewsky, 2012).

\section{Method}

The aim of this case study was to establish how the role of PL was interpreted by different stakeholders and clarify salient aspects of the role. The study focuses on PLship at the workgroup level (cf. Trowler and Knight, 2001) within a single school in a pre-1992 university, and is limited to taught Masters programmes-a fact which precludes the generalisability of the findings to the wider population, although it may reflect the nature of role in similar institutional contexts.

As in previous studies (e.g. Vilkinas \& Ladyshewsky, 2012), I sought to gather data from PLs themselves. Following an exploratory discussion with a PL from another institution, which suggested key areas for inquiry, I engaged seven PLs in semistructured interviews.

An element missing from prior work in this area was the students' voice; I felt it was important to explore their perspectives on the role as a counterpoint to PLs' own accounts. I opted for an open-question format, since I was dealing with a comparatively small, manageable population (Cohen et al., 2011). After piloting the questionnaire on native and non-native English speaking students, and modifying the language for clarity, I used an online survey tool to collect responses. Out of 264 taught Masters students in the school, 54 (20\%) replied, and their responses were clumped into categories in the course of analysis.

\section{Students' Perceptions of Programme Leadership}


Roles and Responsibilities

Table 2 shows students' perceptions of the roles and responsibilities of PLs as indicated in their responses to the survey.

Table 2 Students' perceptions of the role and responsibilities of PLs

\begin{tabular}{|l|c|c|c|}
\hline \multicolumn{1}{|c|}{ Role/Responsibility } & Home/EU & Int. & Total \\
\hline 1. Support students & $71 \%(24)$ & $25 \%(5)$ & $54 \%(29)$ \\
\hline 2. Coordinate teaching & $50 \%(17)$ & $25 \%(5)$ & $41 \%(22)$ \\
\hline 3. Design/develop programme & $44 \%(15)$ & $20 \%(4)$ & $35 \%(19)$ \\
\hline $\begin{array}{l}\text { 4. Ensure quality (of teaching, resources, } \\
\text { environment) }\end{array}$ & $29 \%(10)$ & $15 \%(3)$ & $24 \%(13)$ \\
\hline $\begin{array}{l}\text { 5. Share information and facilitate } \\
\text { communication }\end{array}$ & $9 \%(3)$ & $40 \%(8)$ & $20 \%(11)$ \\
\hline 6. Evaluate programme & $15 \%(5)$ & $15 \%(3)$ & $15 \%(8)$ \\
\hline 7. Ensure students' learning* & $21 \%(7)$ & $5 \%(1)$ & $15 \%(8)$ \\
\hline 8. Teach and mark assignments & $21 \%(7)$ & $5 \%(1)$ & $15 \%(8)$ \\
\hline 9. Coordinate assessment (not including & $15 \%(5)$ & $5 \%(1)$ & $11 \%(6)$ \\
\hline support) & $15 \%(5)$ & $5 \%(1)$ & $11 \%(6)$ \\
\hline 10. Lead teachers and other staff & $12 \%(4)$ & - & $7 \%(4)$ \\
\hline 11. Indicate further learning opportunities* & $15 \%(3)$ & $7 \%(4)$ \\
\hline 12. Organise enrichment activities & $12 \%(4)$ \\
\hline 13. Promote programme and recruit students & & & $7 \%(4)$ \\
\hline
\end{tabular}

The top ranking item, Support Students, was chosen by over half of the respondents, however home/EU students were almost three times more likely to identify this role. The most common role international students identified was Sharing information and facilitating communication, for example: 
[PLs should] interact...with classmates and tutors so that they can understand better each other. (International student)

This variation might reflect the fact that international students have travelled further to study in Europe, are more socially isolated, and consequently have a greater reliance on PLs to facilitate communication.

I define 'enrichment activities' (Table 2, item 12) as activities in addition to, and which supplement, the taught and assessed elements of the programme. International students were five times more likely than home/EU students to identify this item, which might indicate their greater appreciation for, or participation in, activities such as institutional visits.

The starred items (7, 8 and 11) are problematic since-to a greater or lesser extent-they may reflect PLs' activities as tutors rather than PLs.

\section{Contact with Programme Leaders}

Seventy percent of students reported having contacted their PL with a 'request, problem or concern'. Some of these related to requests for generic information on assessment criteria, referencing conventions or internet resources. Almost a fifth of responses refer to PLs' guidance and feedback on assignments, which probably reflects their tutorial rather PLship responsibilies; however, a number of the responses offer important insights into students' perceptions of the role of PLs.

Some responses evidence PLs' responsibility for managerial problem solving, as well as ensuring the quality of provision (Table 2, item 4):

Once I...approached [my PL] with a problem of too many students in one class. He promptly split the group into two and assigned a new tutor. (International student)

My tutor was not available [to] read my draft essay. The programme leader responded promptly. (Home/EU student) 
These responses show PLs responding to concerns as they arise and, in the second instance, 'stepping in' for a colleague to ensure the quality of provision.

Students approached PLs with a range of personal difficulties, including sickness, problems at home and work, and academic issues. PLs supported students by approving requests for extensions, solving problems with placements, and providing emotional support:

I required several extensions for submitting course work and the programme leader was always supportive and accessible. Without her support it is unlikely that I would have been successful in completing the course. (Home/EU student)

When I couldn't finish the course on time due to family reasons, she was very helpful, understanding and guided me how to continue. (Home/EU student)

I felt so bad about a course I failed. She was there for me and gave support [so] that I would not fail my MA. (Home/EU student)

PLs are portrayed as highly engaged practitioners, eager to advance students' understanding through individualised guidance and support:

The PL has always made time to speak with me and help me take my learning a step further. I have valued this active discussion much more than listening to didactic sessions. (Home/EU student)

Although the survey was not intended to elicit data on the extent to which students felt that PLs had fulfilled their responsibilities, many students volunteered this information. Seventy-nine percent of students either praised their PL directly or expressed a positive value judgement such as 'dealt with promptly'. These responses include expressions of gratitude and admiration:

She was always eager to reply [to] me, even a minute after I emailed her....I admire her academic and friendly behaviour during our discussions and emails. (International student)

This 'groundswell' of praise may indicate that students who had received support from their PL were eager to reciprocate by praising him or her through an 
anonymous survey. Speed of response was a major issue for students: 16 students (42\%) referred to the speed of PLs' responses; 14 did so positively, and two negatively.

\section{Programme Leaders' Perceptions of Programme Leadership}

The main themes emerging from interviews with the PLs were the nebulous nature of the PL's role; PLs' responsibilities for managing the quality of the programme; and the administrative aspects of the role.

\section{Role Defined by Practice}

A number of PLs expressed what they perceived was a lack of clarity in the role:

[My reason for] agreeing to do this [interview] is partly because I never really think about what the role involves actually. Nothing is written down, as far as I'm aware, regarding the responsibilities of the role....A written description of what the role involves? I've never seen such a thing. (Neil, $P L$ )

I should say that it's never been spelled out to me what the job involves. I took over a couple of years ago from [a colleague]...and I just do what he did. (Nicola, $P L$ )

If there is a job description I don't think I've read one [laughs]. Now, that could be my fault, I mean there may be one somewhere on the website. Knowing how bureaucratic the institution is, I'm sure there will be one-there seems to be a form for every feasible human activity within the university. I've just tended to forge ahead with leading the programme from my particular standpoint. (Emma, PL)

An institutional role description for PLs did exist, but no PLs showed an awareness of this formal documentation.

The seven PLs I interviewed were roughly split down the middle in terms of their degree of clarity on the role. From Emma's words above it can be seen that, while she might be unclear about the formal, institutional expectations of the role, this does not overly trouble her: she tends to "forge ahead". Indeed, those with the greatest 
confidence in their interpretation of the role were those who took an empowered stance which incorporated elements of leadership and management. For Gabriela, what distinguished PLship from other roles was the perspective it offered:

[PLship] is about me making sure I have an overall view of the whole programme, so I can make sure that the modules and the teaching for the modules and the support between the modules, the stuff on the VLE all links in to make a coherent programme, because I'm the person with the overview of all of that. (Gabriela, PL)

The three PLs who expressed the greatest uncertainty claimed in near-identical terms that they had "never really thought much" about their role, which they regarded primarily as administrative. Nicola explained that, in inheriting the role from a predecessor, she "just did what he did." For Neil, too, the process of 'becoming' a PL involved aspects of conscious and unconscious imitation. While his memory was not clear on the matter, he tentatively explained that on inheriting the role he

probably asked the person who I took it over from...it's kind of all very informal. I would probably have asked him "What did you do?" and he would have told me....I suppose...the very first time I took on an administrative role I would have had to learn more directly, more explicitly about what was involved. (Neil, PL)

These accounts reflect aspects of informal, situated, peer-learning consistent with Wenger's (1998) work on communities of practice. The fact that PLs 'came to know' their role informally, through participation, can explain why some PLs were seemingly unable to outline the precise responsibilities of the role:

I'm sure I do loads of things but I never really sort of thought about what I do. One thing seems to merge into another. (Nicola, $P L$ )

It is understandable if some PLs were unable to clearly articulate their role in a spontaneous, interview situation-particularly if the role had never been "spelled out", to use Nicola's phrase, and there had been no prior reflection on the role's precise function and remit.

From Kevin's perspective, PLship depended very much on the inclination of the postholder. For him, the role could be described either in a formal, pragmatic way, in terms of a "litany of tasks", or "a more cerebral way, in terms of vision and strategy, 
and ambition and passion." This reflected varying degrees of commitment, as he explained:

If you have someone leading a programme who doesn't have a purposefulness about their approach, it will be very different to someone who said "Actually, I care about this, and therefore I'll put the extra time in"...One could imagine a programme being run by someone who doesn't have 'that' to any great degree, who could do programme leadership as a very functional task...[but] an effective programme leader should be combining [functional tasks] with this other visionary, strategic, planning, development stuff. (Kevin, $P L)$

It is clearly possible to discharge PLship responsibilities without moving far beyond the administrative level, but effective programme leaders offer something extra. This additionality might be motivated by a sense of commitment to the field or the students, as Kevin suggested above.

A view offered by a few PLs was that leadership was not so much dependent on the individual as on the needs of the programme. Some programmes simply required administration and management, while others-notably those under threat or in crisis-required leadership for survival. This would suggest that leadership is needed intermittently.

Whether or not PLs regarded their role as ill-defined, they all recognised its importance. They took pride in their programmes, which they felt were of high quality. As Nicola said: "it's a prestigious and for many people a life-changing thing." They also took pleasure in knowing that they had personally contributed to the success of their students.

It's great to know that people have used the degree [laughs] to get on, and it gives you that feeling that what you've done is useful. (Emma)

PLs showed satisfaction in their former students receiving high-level appointments, gaining access to doctoral study, or simply re-entering society "with a different set of views" (Kevin).

Another gauge of the 'importance' of a role, is its status within a hierarchy. Positional authority does not accompany the role of PL (except incidentally, as in the case of 
Thashika, who was a professor), so PLs' ability to influence practice was key to their management of quality, as will be explored in the next section.

\section{Managing Quality}

Five key topics were involved in programme quality management:

i) Programme development and delivery

ii) Student recruitment

iii) Student support

iv) Enrichment activities

v) Fostering external networks

\section{i) Programme development and delivery}

One PL, Gabriela, had been responsible for creating the programme she now led, and offered insights into the process. She had been in a small working group which, having identified the need for a programme, approached the university and a governmental agency to seek funding. Following this, there had been extensive stakeholder involvement in developing the curriculum, since the programme needed to meet external funding and professional accreditation criteria. The programme then recruited and continued to develop in line with other existing programmes (see below), and ongoing modifications did not require stakeholder re-approval.

In all but one of the programmes under investigation, the perceived need for programme development was minor and routine, in response to ongoing developments in research and inputs from staff and students. Neil explained that as long as a programme recruited in line with expectations there was no cause for major programme development.

Because it's been recruiting very well we haven't been forced to think hard about - you know, why change - why rock the boat, as it were? So I haven't been forced. But we tweak it. For example, changing slightly the support students get for their portfolio; drawing up supplementary criteria for the 
assessment of that; changing the order of how one of the core modules was taught, that kind of thing. (Neil, PL)

The perceived need for programme development was informed by student evaluations, external assessment reports, the market response, developments in research and the field, informal discussions and formal reviews with colleagues in the programme team, and PLs' personal reflections.

Thashika's programme was 'in crisis', having experienced recruitment failure in line with national trends in her subject. Her response was to take the programme team on an 'away day' to review their curricula from top to bottom, consider new content and marketing (including for international students), and alternative delivery methods, such as a summer school format.

Although PLs made structural decisions about delivery, they had less input on the implementation of modules within their programme.

It's difficult for me to dictate what happens in another module...Whilst you have a role in developing the programme as a whole, you can't in the end determine what happens in an individual module. (Takumi, $P L$ )

Yet PLs did influence the day to day delivery of their programmes: through recruitment ("I've picked people who I know are going to be good", Gabriela); through informal discussions; and through professional development:

My job...is to find ways, first of all, of supporting and mentoring colleagues...An obvious example of how that mentoring might feature is in getting colleagues to sessions that I teach—first of all in an observational role, but very quickly in terms of a participatory role...So, positional authority? No. But...professional development for the individual concerned? Yes. (Thashika, $P L)$

ii) Student recruitment

Student recruitment is closely linked to a programme's quality, affecting its perceived status in addition to its economic and academic viability. PLs made programme-level 
decisions affecting the size and profile of the student body, and discretionary judgements at the level of individual applicants.

All student applications were processed by the school's Admissions Office, which checked whether applicants fulfilled eligibility criteria provided by PLs, including minimum qualifications, proof of language proficiency (for non-native speakers of English), and in the case of six out of seven programmes, a specified period of relevant professional experience.

The extent of PL-involvement in the recruitment process varied between programmes. Neil and Nicola worked in an academic team which regularly recruited $60+$ students for taught Masters study. For their programmes, Admissions Office staff made offers to applicants directly, subject to the fulfilment of the minimum criteria.

I don't have anything to do with that - thank goodness, because we get hundreds [of applications]. (Nicola, PL)

These PLs were only consulted if an applicant's experience or qualifications were ambiguous.

The five remaining PLs reviewed applications individually. This was no doubt made easier by the comparatively smaller volume of applications, but it also seemed to reflect their desire to ensure that applicants were suited to the programme.

It's not a requirement [to check each application], but I do...I want to know the IELTs is right - if it isn't it can be put right over time...I want to see their personal statements...to see what that tells me. (Kevin, $P L$ )

These PLs explained the importance of judging each application on its merits, as it would serve neither the applicants' nor the programme's interest to enrol students who would be ill-suited to the programme.

You need to ensure that people who are investing a year of their life...(and their money) are going to be in a position to benefit from it. (Kevin, $P L$ )

If they don't have an interest in the area...they're going to struggle with the reading because it's not going to be relevant to them...I'm not under pressure to take students who are not suited to the course...It's not in anybody's 
interests to take students who are going to struggle...Particularly for students if they end up failing. (Takumi, $P L$ )

A few PLs expressed the view that Masters level study could be transformative, and for this reason it was important to recognise the potential of applicants, rather than adhering to uniform entrance criteria. Emma believed that a PL's discretion should be exercised optimistically:

I interpret [entrance requirements] quite liberally. I try to take each case on its merits... One academic did say 'If we want to achieve the vice-chancellor's mission of being one of the top 50 universities in the world by $2015 \ldots$ then one way of achieving that is ensuring we're very, very selective in terms of who is admitted to the programmes.' The other view is to say 'Well look, we are offering a service' - and I tend to be quite generous in giving people a chance, an opportunity, by looking for strengths rather than weaknesses which might disqualify someone from being on the course. And I would argue that that more generous, humanistic approach has been justified in terms of the success that many of these students have enjoyed. (Emma, PL)

A compromise position was expressed by Gabriela: since her programme limited its recruitment to 'mid-career' professionals, rather than rejecting an applicant outright, she might ask them to "go away and try to get more experience and apply in a couple of years."

All PLs felt that it was important to have minimum standards for entry: "keeping the [entry] standards right is important for keeping the quality of the course right," as Thashika expressed it. For one PL, raising entry requirements had been a priority for improving the quality of the programme:

One of the first things I did when I became [PL] was help make a decision about the English language requirement...We...felt that some of our students were struggling with the demands of academic reading and writing, especially those who were coming to us with an IELTS score of 6.5. (Nicola, PL)

However, raising the entry requirements also reflected the need to maintain the status or 'prestige' of the programme in relation to others'.

All of our immediate competitors were raising the bar. So, like it or not, there is a sort of prestige thing there. If you're hoping to attract the highest calibre 
candidates...they're more likely to go for a course which is more difficult to get onto. (Nicola, $P L)$

PLs set the 'standard' in the heraldic sense of a flag bearing an army's insignia: minimum entry requirements are a sign to students and 'competitors'. Even when programmes under-recruited, PLs were not pressured into lowering entrance criteria; as Thashika explained, this would be "detrimental" and "counter-productive":

So, we let weaker students through (to put it crudely). Who's that going to help? It's not going to help the students, it's not going to help the quality of our course, it's not going to help other students' experience on the course...We're a good course! That's the whole point! You've got to be good to get onto our course, that's why you should come here. (Thashika, PL)

Students' perception of a programme's quality is necessarily dependent on their own subjectivity, but it is influenced by PLs in several ways, including through their selection of the cohort. This is why PLs regarded it as their responsibility to "maximise the recruitment of the 'most able' applicants" (Emma).

The 'calibre' of the intake was not PLs' only concern in managing recruitment for quality. It was seen as important to ensure that at least a minimum number of students were recruited, for academic as well as economic reasons. Thashika explained that, in her opinion, "the synergies you get from...students working together are harder to establish in a [small] group of six to eight students." For this reason, she had experimented with combining her students with those of another programme in order to provide a minimum class size.

\section{iii) Student Support}

PLs provided academic and non-academic guidance to students, and mediated with other staff members over various disagreements involving module selection, assignment titles and marks.

Takumi saw the supportive side of his role as "being the first port of call for students who have problems". This was especially important on his programme, since $2 / 3^{\text {rds }}$ of his students were 'distance' learners, and although "hypothetically they have a 
personal tutor... they don't know that person". Students came to him with a range of issues:

Sometimes they're academic things 'I'm not happy with the mark I got for this assignment,' sometimes: 'I've got huge problems at work and I'm not going to be able to keep up, what can I do?' (Takumi, PL)

Nicola, too, discussed this dual role:

When the students come, of course, I'm in some sense responsible for them. They do have a personal tutor, but...if they've got any sort of administrative issue with the course they tend to come to me. And also if they've got any other problem they tend to come to me as well...They realise that I...can help sort things out if they've got a problem. (Nicola, $P L$ )

It is not clear how far Nicola regarded this as a legitimate part of her role, and how much she saw it as an imposition.

Only one PL discussed her role in initiating student support, before it was requested.

Every now and then I sit with my support officer and I go through all the students' [files] and we work out 'Where are they, are they on track? That person's got an extension, this person's on mitigating circumstances, when are their hand in dates?" And we just make sure everyone's going okay...If I haven't heard from a person in a while I'll do a little email "How are you, what's happening?" (Gabriela, PL)

Thus, Gabriela saw her role as including the regular monitoring of students' progress. To facilitate this she kept students' photographs on the wall beside her phone, to help her link names to faces.

\section{iv) Enrichment}

Most PLs were involved in organising what I have termed 'enrichment' activities. For Emma, 'institutional visits' represented "a significant need in terms of improving the quality of the programme," while Nicola explained the benefits of an annual student conference in some detail: 
We need to show students that what they do is...important enough to talk about in a public space. And so we do it quite formally: we have a guest speaker, we get catering, have a proper programme and so it gives what they're doing some kind of status, makes them feel-l hope-that what they're doing is worthwhile. (Nicola, $P L$ )

The nature and degree of organisation involved in different enrichment activities varied significantly. As might be imagined, arranging conferences was "quite a job". In other cases, PLs' responsibilities included securing funding, staffing or institutional approval.

\section{v) Fostering External Networks}

Most PLs discussed their role in fostering links with external individuals and institutions. This was motivated by a range of needs, including programme enrichment, benchmarking and comparison, marketing and research. Examples of each are given in the following bullet-points.

- Teaching and programme enrichment. Gabriela's programme required interdisciplinary tutors with diverse specialisms. She sought to extend her network, bringing in new people to present on particular topics, which sometimes led to them being appointed to teach.

- Benchmarking and comparison. Thashika's work as an external examiner helped her analyse how programmes were run at different institutions, including aspects of structure, module composition and assessment. This helped her recognise that issues with recruitment were a sector-wide problem, rather than something limited to her own institution.

- Marketing. Links with alumni were exploited to attract new students: "the best marketing tool is word of mouth" (Nicola). Kevin regularly invited former students to attend international recruitment events.

vi) Research. Gabriela spoke of the role she hoped her alumni would play in researching her field. She offered workshops and mentoring to former students to encourage them to develop their critical studies for publication, as developing a research base was important for the long-term survival of her programme. 


\section{Administration}

Specific paperwork involved in PLship included maintaining programme information, fliers and the website, as well as the programme review. One PL felt that the paperwork associated with the QA process was helpful in ensuring quality:

It's quite useful for me to reflect on these issues and feel satisfied...that we've taken these particular steps since last year and these are the priorities for next year. (Emma, $P L)$

However, in the majority, PLs' attitudes towards the administrative aspects of their role were negative: they reported frustration, a sense of futility, and a feeling that these tasks should be done by someone else: "I'm paid too much really for some of the stuff I do" (Gabriela). Arguing against the QA paper trail, Thashika felt that the 'Student Evaluation' was unreliable ("they're so polite on their evaluation forms it's ridiculous") and that there were better measures of gauging student opinions, such as observation and discussion in class.

Timetabling was another administrative duty for PLs, and the burden was extremely variable. For some it was negligible, while for those with a delivery team of ten, it could be overwhelming. Another task which PLs seemed to hold in low regard was recruitment predictions. While managing the quality of a programme required a practical knowledge of the market and the competition, which was a genuine concern for PLs, quite separate to this was the bureaucratic requirement of predicting student numbers for the following year. Despite knowing the number of offers made, PLs had serious doubts about their ability to accurately predict the number of students who would register in any given October, which they felt was dependent on geopolitics and the vicissitudes of global economics. Even the PL who worked exclusively with students from a single sector in the UK felt she had little control over various factors which would strongly affect the accuracy of recruitment predictions; even though $50 \%$ of her students received government-funded places, Gabriela only found out in June that external funding would be available for October, which was several months after recruitment predictions were due in the system. 
Several PLs explained that the administrative side of the role often involved pursuing changes through the bureaucracy. Nicola felt that, since many programme-level decisions were made collegially within her academic team, administration was "the most salient part of the job." A few PLs discussed the importance of effecting changes "without committees" - i.e. by by-passing the committee stage, effectively introducing changes around the bureaucracy. This was important from the point of view of time, as making 'official' changes through the committee process could result in a delay of a year or more. One result of this was that PLs were more disposed towards making minor modifications (e.g. by combining classes for a single module, or making a module 'optional') rather than major changes (e.g. to the delivery format) which required a significant burden of paperwork.

\section{Discussion}

Like 'street-level bureaucrats' (Trowler \& Knight, 2001), PLs have considerable autonomy in how they interpret their role. In some ways this accounts for the variation in practice, although the contextual demands of specific programmes also influences the nature of PLship. While administrative and managerial responsibilities are continual, the need for leadership is contingent, and especially important for avoiding or manoeuvring through times of crisis.

Students recognised the broad remit of PLship, and were able to correctly identify a range of specific responsibilities undertaken by PLs, including designing, developing and evaluating programmes, ensuring the quality of delivery, and recruiting students. In particular, they emphasised PLs' role in supporting students, whether academically or otherwise, and discussed their role in signposting further learning opportunities and offering guidance on future careers. Students placed a high value in the work of PLs: some felt that they would not have passed were it not for PLs' interventions, and their responses indicate a reliance on PLs to 'take their side' in a number of ways, offering extensions on assignments and mediating with colleagues-all of which were supported by PLs' own accounts.

From an institutional perspective, various aspects of the role are ignored altogether. There was no formal acknowledgement of the non-academic support provided by PLs, yet it was a service highly valued by students. Equally, PLs' involvement in 
enrichment activities did not appear in institutional guidelines and is overlooked in previous studies; yet most of the PLs interviewed organised enrichment activities (such as institutional visits, student conferences and academic publishing tutorials), although few students acknowledged this. A lack of personal reflection and wider acknowledgement of PLs' work may contribute to a reductive view of PLship, yet the PLs in this study had a vital role in maintaining the relevance of and demand for their programmes, and providing a transformative experience for students.

In some ways PLs' accounts-especially regarding administration-supported MacFarlane's (2007) 'line of visibility' (Figure 1). But there was no evidence that PLs felt that serving students was in any way disesteemed. On the contrary, PLs seemed to be highly engaged with-and on the whole happy with-'low visibility' student services; there was also evidence that PLs reached 'higher visibility' levels of service (such as discipline-based and public service) vicariously, through their students. This is reflected in PLs' expectations in the future research, employment and societal changes that will result from students participating in their programmes. Where PLs felt frustration, it was not from a lack of recognition, but from what they regarded to be the waste of their time and skills on administrative tasks. This leads me to question the value MacFarlane attaches to 'esteem' as a motivator for academics' work: the PLs in this study were more motivated by the desire to do their job well for the benefit of students and wider society. A further challenge to MacFarlane's article relates to the micropolitics of service, which the present study indicates is more complex that he acknowledges. While MacFarlane holds that "senior academics largely perform service roles with power and status", and equates PLship with the lower rungs of visibility and esteem, the PLs in my study had high academic status (one professor and six senior lecturers). In arguing that micropolitical factors affect the allocation of service responsibilities in line with their comparative esteem, MacFarlane overlooks the fact that activities are often grouped around roles: the role of PL incorporates numerous discreet activities, some of which fulfil MacFarlane's interpretation of 'esteemed', and some 'disesteemed'.

\section{Conclusion}

This study identifies variations in practice and some confusion, as well as confidence, in the role of PLs. PLs come to know their role informally, and there is room for a 
clearer articulation of institutional expectations; much of PLs' work for students is not acknowledged in institutional guidelines. Rather than focusing on administrative tasks, the role description should reflect the role of PL as it is enacted. PLs may well benefit from peer support activities to reflect on and clarify their role, share practices, and receive greater institutional acknowledgement for their work.

A strength of this study is the inclusion of students' perspectives, an area previously neglected. Students' perspectives are crucial to an understanding of PLship, as these necessarily impact on the role's enactment. The study is limited both in its institutional focus on a single school in a pre-1992 university, and in being confined to taught Masters programmes. As such, the practices outlined here are unlikely to reflect undergraduate programmes with distinct roles for admissions tutors and PLs, or pre-1992 universities which operate within more formalised frameworks; however, the findings may well reflect the realities of similar institutional contexts.

\section{References}

COHEN, L., MANION, L., \& MORRISON, K. (2011). Research Methods in Education - 7th Ed. Research Methods in Education, Routledge.

EVANS, L., \& ABBOTT, I. (1998). Teaching and learning in higher education. London, Cassell.

EVANS, L. (2008). Professionalism, Professionality and the Development of Education Professionals. British Journal of Educational Studies. 56, 20-38.

EVANS, L. (2012). Leadership for Researcher Development: What Research Leaders Need to Know and Understand. Educational Management Administration \& Leadership. 40, 423-435.

HOWSON, F. J. (2012) Enhancing Programme Leadership at Edinburgh Napier University. Edinburgh Napier University. Accessed on 10/08/12. Available at: http://staff.napier.ac.uk/services/hr/development/acprofdev/roles/programmeleaders/ Documents/PLreport2012.pdf.

JOHNSTON, V. \& WESTWOOD, J. (2007) Developing a framework for the professional development of programme leaders. The Higher Education Academy. 
Accessed

on

10/08/12.

Available

at:

http://www.heacademy.ac.uk/assets/documents/johnston final report.pdf.

KNIGHT, P. \& TROWLER, P. (2001). Departmental leadership in higher education.

Buckingham, Society for Research into Higher Education.

KOGAN, M. \& TEICHLER, U. (2007). Key challenges to the academic profession. Kassel, Jenior.

KRAUSE, K. in TIGHT, M. ed. (2009). The Routledge international handbook of higher education. New York, Routledge.

MACFARLANE, B. (2007). Defining and Rewarding Academic Citizenship: The Implications for University Promotions Policy. Journal of Higher Education Policy and Management. 29, 261-273.

McLEOD, C. (2010). Developing and Supporting Programme Leadership at Edinburgh Napier University. Edinburgh Napier University. Accessed on 10/08/12. Available at: http://staff.napier.ac.uk/services/hr/development/acprofdev/roles/programmeleaders/ Documents/Programme\%20Leading\%20Report FINAL 16Dec2011.pdf.

MILBURN, P.C. (2010). The role of programme directors as academic leaders. Active Learning in Higher Education. 11, 87-95.

MORLEY, L. (2003). Quality and power in higher education. Maidenhead, Society for Research into Higher Education \& Open University Press.

RAMSDEN, P. (1998). Learning to lead in higher education. London, Routledge.

TIGHT, M. (2009). The Routledge international handbook of higher education. New York, Routledge.

TROWLER, P., \& KNIGHT, P. (2000). Coming to Know in Higher Education: theorising faculty entry to new work contexts. Higher Education Research and Development. 19, 27-42.

VILKINAS, T., \& LADYSHEWSKY, R. (2012). Leadership behaviour and effectiveness of academic program directors in Australian universities. Graduate School of Business, Curtin University. 
WENGER, E. (1998). Communities of practice: learning, meaning, and identity. Cambridge, UK, Cambridge University Press. 